\title{
PENATALAKSANAAN PERDARAHAN POSTPARTUM DI NEGARA BERKEMBANG
}

\author{
Management of Postpartum Hemorrhage in Developing Countries
}

\author{
Dwi Kartika Cahyaningtyas ${ }^{1}$, Siti Mardiyah WD ${ }^{2}$, Evi Diliana Rospia ${ }^{3}$ \\ ${ }^{1}$ Jurusan Kebidanan, Universitas Muhammadiyah Mataram, Indonesia \\ ${ }^{2}$ Jurusan Kebidanan, Universitas Muhammadiyah Mataram, Indonesia \\ ${ }^{3}$ Jurusan Kebidanan, Universitas Muhammadiyah Mataram, Indonesia \\ Korespondensi: Dwi Kartika Cahyaningtyas dan ayawika99@gmail.com
}

\begin{abstract}
ABSTRAK
Latar Belakang: Kematian berhubungan dengan kehamilan, persalinan ataupun masa nifas. Upaya yang dilakukan dalam menurunkan angka kematian ibu tidak hanya diketahui dari tingginya cakupan, akan tetapi dapat diketahui dari kualitas pelayanan yang lebih menekankan pada kebutuhan kompetensi tenaga kesehatan, kelengkapan obat, peralatan, sarana dan prasarana disemua layanan kesehatan. Berdasarkan organisasi kesehatan dunia menytakan bahwa terjadinya kematian maternal tiap tahun 140.000 atau 1 wanita tiap 4 menit. Tujuan Penelitian: Untuk mengetahui efektivitas dari setiap penatalaksanaan perdarahan postpartum. Metedologi: Delapan tahap untuk scoping tinjauan digunakan dalam ulasan ini. Delapan tahapan meliputi: mengidentifikasi permasalahan kebidanan, prioritas masalah dan pertanyaan penelitian, framework data primer dan sekunder, indentifikasi studi yang relevan, prisma flow diagram, critical appraisal, analisa data ekstraksi data. Hasil: Sebanyak 9 jurnal yang ditemukan, kemudian melakukan analisis tematik dalam bentuk scoping review digunakan untuk mengidentifikasi point-point utama. Kami mengklasifikasikan point-point utama dalam lima tema yang muncul: pemberian carbetocin, pemberian oxytocin, pemberian misoprostol sublingual, pemberian bakri balloon, pemberian tamponade Kondom kateter sebagai penatalaksanaan perdarahan postpartum. Kesimpulan: Efektifitas dari setiap penatalaksanaan perdarahan postpartum mampu menjadikan acuan perbaikan dalam menangani perdarahan postpartum yang hingga saat ini masih menjadi ancaman angka kematian ibu tertinggi di dunia.
\end{abstract}

Kata Kunci: Penatalaksanaan; Perdarahan Postpartum; Persalinan Pervaginam.

\section{ABSTRACT}

Background: Death is related to pregnancy, childbirth or the puerperium. Efforts made in reducing maternal mortality are not only known from the high coverage, but can be seen from the quality of service which emphasizes the competency needs of health workers, completeness of drugs, equipment, facilities and infrastructure in all health services. Based on the World Health Organization states that the occurrence of maternal deaths every year 140,000 or 1 woman every 4 minutes. Research Objectives: To determine the effectiveness of each postpartum hemorrhage management. Methodology: Eight stages of review scoping were used in this review. The eight stages include: identifying midwifery 
problems, priority problems and research questions, primary and secondary data frameworks, identification of relevant studies, prism flow diagrams, critical appraisals, data extraction data analysis. Result: A total of 9 journals were found, then carried out a thematic analysis in the form of a scoping review used to identify the main points. We classified the main points into five emerging themes: carbetocin administration, oxytocin administration, sublingual misoprostol administration, bacterial balloon administration, and tamponade condom catheter administration for the management of postpartum hemorrhage. Conclusions: The effectiveness of any postpartum hemorrhage management is able to make a reference for improvement in dealing with postpartum hemorrhage which is still a threat to the highest maternal mortality rate in the world.

Keywords: Management; Postpartum Haemorrhage; Vaginal Delivery.

\section{PENDAHULUAN}

Kematian maternal dan neonatal hingga saat ini di Indonesia selalu menjadi topik utama. Kematian bagi neonatal dapat terjadi setiap tiga menit dan setiap satu jam pada satu perempuan. Kematian ini berhubungan dengan kehamilan, persalinan ataupun masa nifas (UNICEF, 2012). Berdasarkan hasil diagram dari SDKI bahwa angka kematian ibu di Indonesia pada tahun 2012 AKI meningkat menjadi 359 per 100.000 kelahiran hidup dan pada tahun 2015 AKI kembali turun menjadi 305 per 100.000 kelahiran hidup (BPS, 2017).

Kematian maternal disebabkan karena 2 hal yaitu penyebab langsung dan tidak langsung. Penyebab secara langsung terjadi kematian sebesar 46,96\% (99 orang) dan penyebab tidak langsung terjadi kematian sebesar 51,4\% (109 orang) dan 1,9\% kematian yang tidak diketahui kasusnya. Penyebab secara langsung kematian ibu terjadi dikarenakan perdarahan, sepsis dan hipertensi. Sehingga menjadi penyebab utama kematian ibu dengan presentasi $37,1 \%$ selama dekade terakhir (Halder et al, 2014).

Berdasarkan organisasi kesehatan dunia menyatakan bahwa terjadinya kematian maternal tiap tahun ada 140.000 atau 1 wanita tiap 4 menit. Laporan dari WHO ada $25 \%$ kematian maternal disebabkan oleh perdarahan postpartum dan diperhitungkan ada $\quad 100.000$ kematian maternal setiap tahunnya (Jekti, 2011). Perdarahan postpartum menjadi penyebab utama kematian ibu setelah melahirkan pada Negaranegara dengan penghasilan yang rendah temasuk Indonesia, terjadi hampir seperempat kematian pada ibu melahirkan di dunia (WHO, 2012)

Penanganan yang dapat
dilakukan pada perdarahan postpartum secara konservatif yaitu tetap menjaga kestabilan volume darah dengan penggunaan kanul yang berdiameter besar melalui jalur intravenal, selalu melalukan observasi bertahap, pemberian cairan kristaloid melalui intravena dan transfusi darah. Pengehantian perdarahan postpartum dalam dilakukan dengan pemberian uterotonika dan menggunakan tamponade uterovaginal (Pardede et al, 2017).

Penanganan perdarahan postpartum dengan profilaksis uterotonika terdapat berbagai jenis dan kombinasi yang ada keunggulan 
dan kekurangan dari masing-masing jenis obat. Adapun jenisnya yaitu misoprostol, oksitosin, metilergometrin dan ergometrin, yang telah dilakukan perbandingan dari setiap jenisnya (Sanjaya Windu, 2012). Faktor resiko potensial terjadinya perdarahan postpartum yaitu plasenta previa, presentasi janin, durasi persalinan, trauma uterus dan serviks pada saat persalinan, dengan riwayat operasi secar, induksi dan augmentasi persalinan, makrosomia, plasenta letak rendah (Kramer et al., 2011).

Angka kematian pada ibu yang tinggi hingga saat ini hanya berputar pada tiga masalah utama yaitu perdarahan, preeklamsiaeklamsia, dan infeksi, sehingga diharapkan adanya upaya yang lebih berfokus pada ketiga masalah tersebut dapat dilakukan melalui setiap peran tenaga kesehatan. Bila ditemukan salah satu tanda bahaya pada ibu maka segera lakukan rujukan pada fasilitas kesehatan yang lengkap peralatan dan dokter spesialis obsgyn, kemudia lakukan pemberian cairan kristaloid sebelum tindakan persalinan berlangsung (Chalid et al, 2017).

\section{TUJUAN PENELITIAN}

Tujuan dari penelitian ini adalah untuk mengevaluasi efektivitas dari berbagai penatalaksanaan perdarahan postpartum di negara bekembang.

\section{METODE PENELITIAN}

Penyusunan Scoping Review ini disesuaikan dengan langkahlangkah Scoping Review.

\section{Prioritas Masalah dan Pertanyaan Penelitian}

Manajemen aktif kala tiga merupakan strategi awal pencegahan. Tindakan komponen utama yaitu pemberian uterotonika, tarikan talipusat terkendali dan masasage uterus. Namun misoprostol memiliki efek samping yang ditimbulkan seperti demam dan menggigil. Sehingga misoprostol menjadi pilihan kedua dengan dosis awal $600 \mu \mathrm{g}$ secara oral ataupun sublingual apabila tidak tersedianya oksitosin. Selain itu ada pemberian carbetocin yang menjadi persamaan kerja dari oksitosin dengan aktivitas kerja uterotonika 4 kali lebih lama dibandingkan oksitosin dengan paruh waktunya 40 menit (Siswosudarmo, 2009).

Pada ulasan penelitian review ini bertujuan untuk mengetahui: 1) apa sajakah penetalaksanaan perdarahan postpartum, 2) bagaimana efektivitas dari penatalaksanaan penanganan perdarahan postpartum.

\section{Framework Data Primer dan Sekunder}

Dalam ulasan ini framework yang digunakan adalah PEOS (population, eksprosure/event, outcome, dan study design). Berikut adalah framework sebagai acuan kriteria inklusi dan eksklusi dalam scoping review ini:

Tabel 1. Framework research question

Tabel 2.1. Framework research question

\begin{tabular}{lll}
\hline & Tabel 2.1. Framework research question \\
\hline Element & Inclusion & Exclusion \\
\hline Population & $\begin{array}{l}\text { Ibu yang melahirkan secara } \\
\text { pervaginam dengan resiko rendah } \\
\text { perdarahan postpartum }\end{array}$ & $\begin{array}{l}\text { Ibu yang melahirkan } \\
\text { secara secar }\end{array}$ \\
& Perdarahan postpartum & \\
\hline Exposure/event & Efectivitas penatalaksanaan & \\
\hline Outcome & perdarahan postpartum di negara & \\
& berkembang & \\
\hline Study Design & Metode kuantitatif dengan desain & Metode kualitatif, jurnal \\
& penelitian Cohort, RCT, jurnal & terindeks scopus Q3 \\
& terindeks scopus Q1 dan Q2 dan & dan Q4 dan dilakukan \\
& dilakukan dinegara berkembang & di negara maju \\
\hline
\end{tabular}




\section{Mengidentifikasi Studi yang Relevan}

Strategi pencarian artikel dikembangkan menggunakan beberapa database, yang hanya berfokus pada peer review article. Penggunaan peer review artikel diharapkan bisa menjamin kredibilitas dalam informasi yang ada pada sebuah karya ilmiah lebih benar, akurat dan seluruh isinya dapat digunakan sebagai sumber data. Adapun keyword yang digunakan dalam mencari artikel sesuai topik adalah sebagai berikut: "prevention" or "management" or "Effectiveness" and "vaginal delivery" or "parity" or "normal labour" and "postpartum hemorrhage" or "postpartum bleeding". Adapun database untuk mencari peer review article dengan sumber yang digunakan adalah Pubmed, Proquest, ScienceDirect.

\section{Prisma Flow Diagram}

Proses penyaringan data yaitu menggunakan PRISMA Flowchart. PRISMA merupakan Prefererd Reporting Items for Systematic reviews and Meta-Analyses, dikembangkan untuk membantu penulis dalam melaporkan systematic reviews (SR) dan Meta-Analyses (MA). PRISMA dinilai tepat digunakan karena penggunaannya dapat meningkatkan kualitas pelaporan publikasi (Peters et al., 2015). Setelah mendapatkan evidence, dilakukan critical appraisal menggunakan form dari Critical Appraisal Skills Programme (CASP) untuk dinilai kualitas dari evidence. Data disaring sesuai dengan kriteria yang peneliti tentukan. Adapun tahap-tahan penyaringan data sebagai berikut:

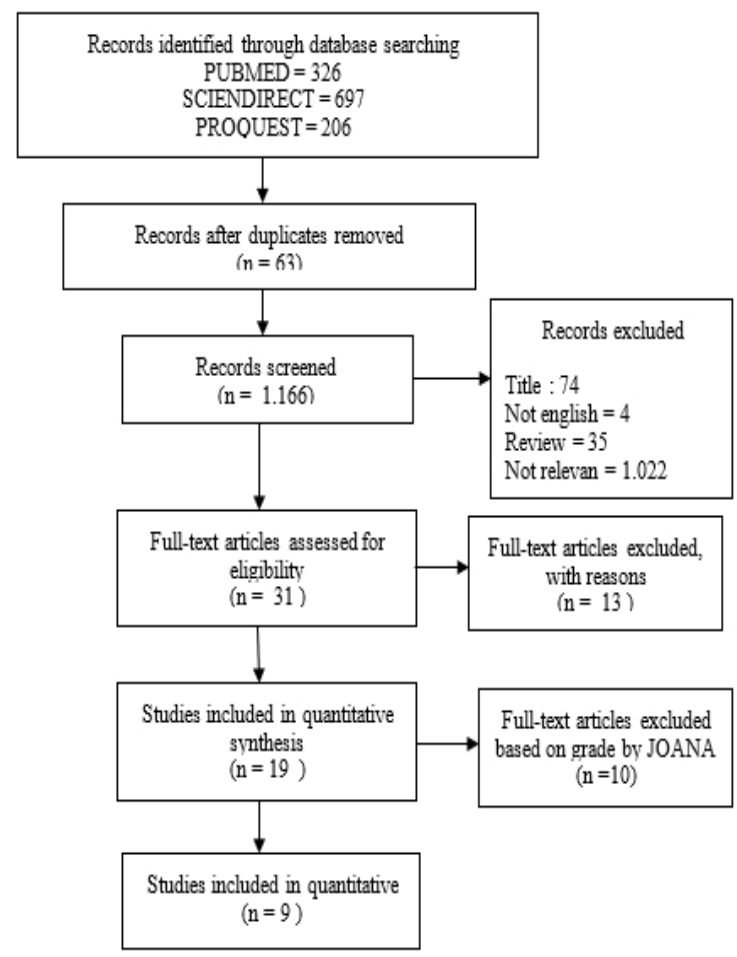

Gambar 1. PRISMA Flowchart

\begin{tabular}{|c|c|}
\hline TEMA & SUB TEMA \\
\hline $\begin{array}{l}\text { Penatalaksanaan } \\
\text { Perdarahan } \\
\text { Postpartum }\end{array}$ & $\begin{array}{ll}\text { a. } & \text { Pemberian Carbetocin } \\
\text { b. Pemberian oxytocin secara } \\
\text { IM dan IV } \\
\text { c. Pemberian misoprostol secara } \\
\text { sublingual }\end{array}$ \\
\hline
\end{tabular}

\section{HASIL PENELITIAN}

Hasil yang didapatkan telah digolong dalam beberapa poin penting terkait penatalaksanaan perdarahan postpartum. Pada hasil ini telah digolongkan intervesi atau perlakukan yang diberikan pada sample penelitian menjadi beberapa golongan sebagai berikut:

\section{Pemberian Carbetocin}

Perbandingan antara oxytocin dan carbetocin memiliki efektitivitas dalam menurunkan perdarahan postpartum, sehingga kebutuhan akan uterotonika lainnya lebih rendah tanpa adanya efek samping. Pemberian carbetocin sebanyak 100 
mg secara IM atau pemberian oxytocin 5 IU secara IM, ditemukan bahwa jumlah perdarahan dan kebutuhan uterotonika tambahan secara signifikan lebih rendah pada kelompok carbetocin (Obstet et al., 2015). Setelah dilakukan berbagai penelitian didapatkan bahwa carbetocin secara IM lebih efektif dari oxytocin dalam pencegahan perdarahan postpartum. Kontraksi uterus dapat terjadi pada pemberian dosis awal hanya dalamkurang dari 2 menit dan akan terus dilanjutkan selama 2 jam (Samimi et al, 2013).

\section{Pemberian Oxytocin}

Kehilangan darah rata-rata pada kelompok oksitosin adalah 75 $\mathrm{ml}$ dengan kisaran 100-550 $\mathrm{ml}$, didapatkan bahwa wanita dengan oksitosin lebih banyak kehilangan darah dibandingkan dengan misoprostol. Namun dalam kelompok misoprostol dengan efek samping menggigil lebih besar dibandingkan dengan oksitosin. Tetapi mual lebih banyak terjadi pada oksitosin dibandingkan dengan misoprostol (Priya et al., 2015). Setelah dilakukan penelitian lain yang diketahui bahwa mayoritas 42 pasien (84\%) dengan oksitosin mengalami kehilangan darah $125 \mathrm{ml}$ sedangkan pada misoprostol 41 pasien $(82 \%)$ mengalami kehilangan darah 126-200 ml, sebagian besar melakukan uji coba dengan membandingkan $600 \mu \mathrm{g}$ misoprostol dengan 10 IU oksitosin, diketahui bahwa oksitosin lebih unggul dari misoprostol, bila oksitosin diberikan secara intravena lebih efektif dibandingkan misoprostol (Tewatia et al., 2014).

\section{Pemberian Misoprostol Sublingual}

Pemberian misoprostol sublingual sebagai tambahan didalam menajemen perdarahan postpartum, didapatkan bahwa dengan menambahkan $400 \mu \mathrm{g}$ misoprostol sublingual dengan 10 IU oksitosin intramuskuler pada wanita dengan faktor resiko tinggi perdarahan postpartum tampaknya lebih efektif daripada oksitosin saja dalam mengurangi perdarahan postpartum sedang (500-999 $\mathrm{ml}$ ) (Chaudhuri et al, 2015). Penggunaan Misoprostol sublingual menyebabkan perdarahan postpartum terjadi lebih rendah daripada oksitosin dalam pencegahan perdarahan postpartum primer pasca persalinan pervaginam dengan dosis $600 \mu \mathrm{g}$ misoprostol sama dengan 10 IU oksitosin. Saat dilakukan perbandingan dengan dosis yang rendah pada misoprostol sublingual $400 \mu \mathrm{g}$ dengan oksitosin $10 \mathrm{IU}$ ditemukan misoprostol lebih efektif dalam pencegahan perdarahan postpartum pada 2 jam postpartum, penelitian ini menggunakan formulasi bubuk sublingual misoprostol (Atukunda et al., 2014).

\section{PEMBAHASAN}

Perdarahan postpartum menjadi hal menakutkan sebab dalam beberapa kasus merupakan masalah yang menyebabkan kematian tertinggi bagi ibu pasca persalinan dalam waktu yang sangat singkat, hal ini dikarenakan setelah persalinan ibu mengalami syok dan menurunkan kesadaran akibat banyaknya darah yang dikeluarkan. Berbagai penatalaksanaan perdarahan postpartum yang telah diketahui sebagai bentuk awal pencegahan dan penanganan tenaga medis pada saat mendapatkan pasien dengan diagnose terjadinya 
perdarahan postpartum primer maupun sekunder.

Penerimaan

oksitosin

intramuskular dan intravena masingmasing dapat mencegah PPH secara signifikan, namun dalam hal ini pada pemberian secara intravena lebih cepat menurunkan kejadian kehilangan darah, ketika oksitosin diberikan secara intravena pencapaian menurunkan dengan kosentrasi yang baik setelah 30 menit. Sebaliknya intramuskular mengahasilkan kerja yang lebih lambat tetapi menghasilkan efek klinis yang lebih tahan lama (Obstet et al., 2016). Akan tetapi berbanding terbalik dengan penelitian Samimi et al , 2013 kebutuhan akan uterotonika tambahan lebih rendah pada Wanita yang menerima carbetocin sehingga dapat diketahui bahwa carbetocin secara IM menjadi alternativ lebih baik disbanding oxytocin secara IM.

Penelitian terus dilakukan pada penatalaksanaan perdarahan postpartum, dengan membandingkan pemberian misoprostol dengan oxytocin secara IM atau IV. Pemberian misoprostol dengan dosis $400 \mu \mathrm{g}$ secara sublingual menjadi alternatif yang aman dan efektif sebagai tambahan menejemen aktif persalinan (Chaudhuri et al, 2012). Namun menurut Chaudhuri pemberian misoprostol dengan oksitosin lebih efektif mengurangi kehilangan darah setelah persalinan pervaginam di antara wanita yang berisiko PPH, yaitu dengan menambahkan $400 \mu \mathrm{g}$ misoprostol sublingual dan 10 IU oksitosin intramuskuler dalam tahap ketiga menejemen wanita dengan resiko tinggi mengarah pada PPH dibandingkan hanya diberi oksitosin saja dalam mengurangi perdarahan postpartum 500-999 $\mathrm{ml}$ (Chaudhuri et al, 2015).

Profilaksis sublingual misoprostol dalam menejemn aktif tahap ketiga persalinan memiliki hasil yang sama dengan oxytocin IM. Namun kehilangan darah postpartum secara signifikan berkurang dalam kelompok misoprostol dibandingkan oxytosin. Meskipun efek samping seperti menggigil dan demam lebih pada misoprostol. Sehingga dapat disimpulkan bahwa misoprostol sublingual sama efektifnya dengan oxytosin intramuskuler sebagai oxytocic prophylactic dalam menejemen aktif ketiga tahap persalinan (Priya et al., 2015).

\section{KESIMPULAN}

Perdarahan postpartum umumnya dapat ditangani secara konservatif. Efektifitas dari setiap penatalaksanaan perdarahan postpartum mampu menjadikan acuan perbaikan dalam menangani perdarahan postpartum yang hingga saat ini masih menjadi ancaman angka kematian ibu tertinggi di dunia. Cara yang lebih efektif dalam penanganan perdarahan postpartum dengan pemberian misoprostol secara sublingual menggunakan bubuk, kemudian pemberian carbetocin secara IV dan IM. Sehingga diharapkan dengan adanya penemuan baru dari jurnal yang telah di review mampu menjadikan perubahan atau penambahan lebih berfokus terhadap efektifas dari management perdarahan postpartum dan juga kemampuan dari setiap tenaga medis yang melakukannya.

\section{DAFTAR PUSTAKA}

Atukunda, E. C., Siedner, M. J., Obua, C., Mugyenyi, G. R., Twagirumukiza, M., \& 
Agaba, A. G. (2014). Sublingual Misoprostol versus Intramuscular Oxytocin for Prevention of Postpartum Hemorrhage in Uganda: A Double-Blind Randomized Non-Inferiority Trial. PLoS Medicine, 11(11).https://doi.org/10.137 1/journal.pmed.1001752

Chalid, M. T., \& Hasanuddin, U. 2017. Upaya Menurunkan Angka Kematian Ibu : December 2016.

Chaudhuri, P., Biswas, J., \& Mandal, A. 2012. International Journal of Gynecology and Obstetrics Sublingual misoprostol versus intramuscular oxytocin for prevention of postpartum hemorrhage in low-risk women. International Journal of Gynecology and Obstetrics, $116(2)$, 138-142. https://doi.org/10.1016/ j.ijgo.2011.09.016

Chaudhuri, P., \& Majumdar, A. 2015. International Journal of Gynecology and Obstetrics CLINICAL ARTICLE A randomized trial of sublingual misoprostol to augment routine third-stage management among women at risk of postpartum hemorrhage. International Journal of Gynecology and Obstetrics. https://doi.org/ 10.1016/j.ijgo.2015.06.064

Halder, A., Jose, R., \& Vijayselvi, R. 2014. Maternal mortality and derivations from the $\mathrm{WHO}$ near-miss tool: An institutional experience over a decade in Southern India. 222-227. https://doi.org/10.5152/jtgga. 2014.14076

Jekti, R. P. 2011. Risk factors of post partum haemorrhage in Indonesia. Health Science Journal of Indonesia, $2(2$ Des), 66-70.

Kramer, M. S., Dahhou, M., Vallerand, D., Liston, R., \& Joseph, K. S. 2011. Risk Factors for Postpartum Hemorrhage: Can We Explain the Recent Temporal Increase? Journal of Obstetrics and Gynaecology Canada, 33(8), 810-819. https://doi.org/10.1016/S1701 -2163 (16)34984-2

Obstet, A. G., Dagdeviren, H., Cengiz, H., Heydarova, U., \& Suzen, S. 2016. Intramuscular versus intravenous prophylactic oxytocin for postpartum hemorrhage after vaginal delivery: a randomized controlled study. Archives of Gynecology and Obstetrics. https://doi.org/10.1007 /s00404-016-4060-7

Obstet, A. G., Mohamed, A., Abdelgany, M., \& Nesreen, M. A. H. 2015. Carbetocin versus oxytocin in the management of atonic post partum haemorrhage ( $\mathrm{PPH}$ ) after vaginal delivery: a randomised controlled trial. Archives of Gynecology and Obstetrics.

https://doi.org/10.1007

/s00404-015-3911-y

Pardede, S.O; Pohan, S.D; Sihombing J.A; Batubara, F. .2017. Penatalaksanaan Kegawatdaruratan Berbagai Disiplin Ilmu Kedokteran.

Priya, G. P., Veena, P., 
Chaturvedula, L., \& Subitha, L. 2015. A randomized controlled trial of sublingual misoprostol and intramuscular oxytocin for prevention of postpartum hemorrhage. Archives of Gynecology and Obstetrics, 292(6), 1231-1237. https://doi.org/10.1007/s0040 4-015-3763-5

Samimi, M., Imani-Harsini, A., \& Abedzadeh-Kalahroudi, M. 2013. Carbetocin vs. Syntometrine in Prevention of Postpartum Hemorrhage: a Double Blind Randomized Control Trial. Iranian Red Crescent Medical Journal, 15(9), 817-822. https://doi.org/10.5812 /ircmj.7881

Sanjaya Windu. 2012. Tanda Bahaya
Serta Penatalaksanaan Perdarahan Post-Partum. 3(1), 9-18.

Tewatia, R., Rani, S., Srivastav, U., \& Makhija, B. 2014. Sublingual misoprostol versus intravenous oxytocin in prevention of post-partum hemorrhage. Archives of Gynecology and Obstetrics, 289(4), 739-742. https://doi.org/10.1007/s0040 4-013-3026-2

UNICEF Indonesia. 2012. Kesehatan Ibu \& Anak. Gambar 2.

WHO. $2012 . \quad$ WHO recommendations for the prevention and treatment of postpartum haemorrhage. In World Health Organization. https://doi.org/10.1016/j.ijgo. 2013.06.024. 